\title{
Discrimination between Chinese Localizers Fujin and Pangbian
}

\author{
Ying Zhang \\ Tianjin College, University of Science \& Technology Beijing, Tianjin, China
}

\begin{abstract}
This paper discriminates between the tricky Chinese localizers in TCSOL fujin (附近) (nearby) and pangbian (旁边) (beside; by). Through a comparative analysis, three rules for the choice of them are identified: Use fujin rather than pangbian when barrier exists, use fujin to express spatial relationship and pangbian for horizontal relationship, and use both with quantity phrases yet only fujin with indefinite quantity phrases. The research is hoped to facilitate the two localizers' acquisition and contribute to the existing inadequate literature in the study of such Chinese localizers.
\end{abstract}

Index Terms—Fujin, pangbian, Chinese locative words, Chinese localizers, TCSOL

\section{INTRODUCTION}

The discrimination of the Chinese locative pair of fujin (附近) (nearby) and pangbian (旁边) (beside; by) is a tricky point in Teaching Chinese to Students of Other Languages (TCSOL), difficult to explain on the part of the teachers and hard to understand to the students as to the subtle differences between them. Researches on differentiating and analysing the pair are rarely found in China, only two papers being closely related (Wang, 2005; Li, 2012). None is found abroad. Many reference books like Modern Chinese Eight Hundred Words (Enlarged Revision) (1999) (Eight Hundred Words hereafter) with Shuxiang Lv (1904-1998) as editor-in-chief do not touch the comparison. However, in the TCSOL practices, both locative words are listed in the Glossary for Grade One in the Teaching Syllabus for College Chinese Majors of Other Languages (2002) (《高等学校外国留学生汉语言专业教学大纲》) published by Beijing Language and Culture University Press and require the students to master. The Syllabus is still authoritative in China's TCSOL. Considering the high frequency of their appearance and the annoying confusion caused by the two localizers, this paper tries to discriminate between them with a view to facilitating their acquisition and contributing to the existing inadequate literature in the research of such Chinese localizers.

\section{LITERATURE REVIEW}

\section{A. Definitions of Fujin and Pangbian}

Only fu (附) and pang (旁) are listed in An Unabridged Comprehensive Dictionary (2009) (《辞海》). The fourth definition for $f u$ is “靠近” (close to; near) (p.652), while the first definition for pang is “边; 侧” (side; by the side of) (p.1708). In The Contemporary Chinese Dictionary (Chinese-English Edition) (2002) (《现代汉语词典》(汉英双语)) (Chinese Dictionary hereafter), fujin is defined as 1. 靠近某地的 (nearby; adjacent; neighbouring); 2. 附近的地方 (close by; in the vicinity of) (p.608). Pangbian means “左右两边; 靠近的地方(beside; by)” (p.1446). In Eight Hundred Words, pangbian and pang mean the same, “近侧; 附近”(close by; in the vicinity) [My translation], while there is no entry for fujin (Lv, 1999, p.424).

It can be seen from the Chinese Dictionary and the Eight Hundred Words that fujin and pangbian are very hard to discriminate in meaning. What is more, the latter uses fujin to explain pangbian, resulting in the misunderstanding that the two locative words are the same.

However, "nearby" in Oxford Advanced Learner's English-Chinese Dictionary (6th ed) (2004) (Oxford Dictionary hereafter) is defined as $a d j$. [usually before noun] near in position; not far away (附近的; 邻近的); $a d v$. a short distance from sb/sth; not far away (在附近; 不远) (p.1153). “Beside" is defined as prep. next to or at the side of sb/sth (在旁边（或附近）) (p.143). Difference does exist between the two words, with "beside" stressing "the side of".

The Chinese localizer “旁边”(pangbian) in itself is a compound spatial word, with “旁” (pang) and “边” (bian). The meaning of bian can help differentiate fujin and pangbian. When bian is combined with pang in its sixth definition into the compound word pangbian, it is defined in the Chinese Dictionary as “靠近物体的地方” (place next to a person or thing) and the compound, as "side" (2002, p.112). As to "side", Oxford Dictionary lists 15 general meanings or contexts (GM for short hereafter), among which six considered relevant are given below in Table I. 
TABLE I.

SIX CONSIDERED RELEVANT GENERAL MEANINGS OF "SIDE" IN OXFORD DICTIONARY

\begin{tabular}{|c|c|c|c|c|}
\hline $\begin{array}{l}\text { GM } \\
\text { No. }\end{array}$ & GM shortcut & $\begin{array}{l}\text { Mng } \\
\text { No. }\end{array}$ & English meaning & Chinese meaning \\
\hline \multirow{2}{*}{1} & \multirow{2}{*}{ LEFT/RIGHT (左; 右) } & 1 & $\begin{array}{l}\text { [C, usually sing.] either of the two halves of a } \\
\text { surface, an object or an area that is divided by an } \\
\text { imaginary central line }\end{array}$ & $\begin{array}{l}\text { （由想像的中线分出的） } \\
\text { 一边，一侧 }\end{array}$ \\
\hline & & 2 & $\begin{array}{l}\text { [C, usually sing.] a position or an area to the left } \\
\text { or right of sth }\end{array}$ & $\begin{array}{l}\text { (事物左方或右方的) 一 } \\
\text { 旁, 一边, 一侧 }\end{array}$ \\
\hline \multirow{2}{*}{2} & \multirow{2}{*}{$\begin{array}{l}\text { NOT TOP OR BOTTOM } \\
\text { (侧面) }\end{array}$} & 3 & $\begin{array}{l}{[\mathrm{C}] \text { one of the flat surfaces of sth that is not the }} \\
\text { top or bottom, front or back }\end{array}$ & 侧面 \\
\hline & & 4 & $\begin{array}{l}{[\mathrm{C}] \text { the upright or sloping surface around sth, but }} \\
\text { not the top or bottom of it }\end{array}$ & $\begin{array}{l}\text { 侧面，斜面（某物四周的 } \\
\text { 垂直面或斜面） }\end{array}$ \\
\hline 3 & EDGE (边缘) & 5 & $\begin{array}{l}{[\mathrm{C}] \text { a part or an area of sth near the edge and }} \\
\text { away from the middle }\end{array}$ & 边缘; 边 \\
\hline 4 & OF BODY (身体) & 6 & $\begin{array}{l}\text { [C, usually sing.] either the right or left part of a } \\
\text { person's body, from the ARMPIT (= where the } \\
\text { arm joins the body) to the hip }\end{array}$ & 侧面; 胁 \\
\hline 5 & $\begin{array}{l}\text { NEAR TO SB/STH (某 } \\
\text { 人/某物的近旁) }\end{array}$ & 7 & [sing.] a place or position very near to sb/sth & 近旁; 旁边; 身边 \\
\hline \multirow[b]{2}{*}{8} & \multirow[b]{2}{*}{ MATHEMATICS (数学) } & 10 & {$[\mathrm{C}]$ any of the flat surfaces of a solid object } & (立体的) 面 \\
\hline & & 11 & $\begin{array}{l}{[\mathrm{C}] \text { any of the lines that form a flat shape such as }} \\
\text { a square or triangle }\end{array}$ & 边 \\
\hline
\end{tabular}

(2004, p. 1622)

\section{B. Studies on Locative Words in Modern Chinese}

Ningsheng Liu, from Department of Linguistics, University of Colorado, studies how Chinese expresses spatial relationships of objects. He explains how to discriminate between goal objects and reference objects with the help of a series of features accompanying them. As to the acceptability of some sentences and the unacceptability of others, he thinks that it mainly attributes to the Chinese language habits. In speech, people are not inclined to put a nominal component with features of being minor, moving, temporary, simple, unknown, etc. in the place of a sentence for location. He also presents the influences of speech categorization on the acceptability of a sentence. He uses the graphic function of speech for the selection of locative words. Liu referred to fujin and pangbian in the fourth part of his paper, "Features of Frame of Reference and the Chinese Locative Word System" and puts both words under Class One of the four groups of Basic Chinese Locative Words, which expresses the relative position of objects, laying special emphasis on the description of distance. Liu thinks that “甲在乙附近” (A is near B) and “乙在甲附近” (B is near A) are the same in meaning and the distance between them is not long, that is, proximal. “甲在乙旁边” (A is beside B) just indicates that A is not far from B but they are of horizontal level (Liu, 1994).

Jingmin Fang (1954-2004), a professor from Faculty of Humanities, Matsuyama University, Matsuyama, Ehime Prefecture, Japan, a Director of the Chinese Association of Japan and an editor of Contemporary Research in Modern Chinese (《现代中国语研究》), in his paper "Basic Strategies in the Cognitive Process of Chinese Spatial Location Reference" referred to the five structural elements of the location reference he proposed as early as in 1993 and 1997 localizer, narrator, point of view, direction reference point and position reference point. He expounds how to choose the observing point, how to choose horizontal locative words, how to decide on the direction reference point and how to select position reference point (Fang, 1999a). However, he did not mention fujin and pangbian.

In another paper of the same year, "The Cognitive Structure of Chinese Spatial Location Reference", Professor Fang exemplifies the five structural elements of the location reference. He explains location reference as a cognitive structure and proposes its structural elements and types. He thinks that the locative words in modern Chinese can be divided into five groups according to the nature of the direction they designate. Of which Group E represents general direction, including pang (旁), jian (间) (between; among; within a definite time or space), zhong (中) (centre; middle), pangbian, fujin, zhouwei (周围) (around), zhongjian (中间) (between; among). Professor Fang thinks that fujin and pangbian represent human recognition of the relative distance between objects, yet he makes no comparative analysis of the two words (Fang, 1999b).

Fang Wang, from Faculty of Arts of Zhengzhou University, Zhengzhou, Henan province, examines fujin, pangbian, liangpang (两旁) (on both sides), zиоуои (左右) (on the left and right) and zhouwei as short-distance locative words with a view to presenting the cognitive semantical meaning of the five localizers. She agreed with Professor Fang (1999b) in that fujin may be in any direction, in the front, in the rear, on the left, or on the right. She adds that fujin suggests short range between an object and the reference point, and its semantic features are not ORIENTATION ([-定 向]) and POSITION ([+位置]) and SHORT RANGE ([+近距]). Fujin and pangbian are grouped into one-way shortrange locative words, which suggest that an object is at a certain direction position of a reference point. Ms Wang approaches the two localizers from the cognitive perspective in the second part of her paper. She thinks fujin and pangbian have obvious differences in terms of position reference as follows: 
1. The sight lines between the object and the viewer are not the same in distance, which is in agreement with Fang's viewpoint in 1999a. Fujin is chosen with a longer sight line and pangbian with a shorter one. In some contexts, both can be used. However, in language sense they still have subtle difference in the length of sight line. In general, pangbian suggests a relatively shorter distance than fujin.

2. Fujin can only be used for off-domain reference (域外参照), while pangbian can be used for both off-domain and in-domain reference (域内参照). For example, we can say “马路旁边停着几辆小车。(A few cars are parked by the road.)”, while “马路附近停着几辆小车。” is not acceptable.

(Wang, 2005)

Sha Li (2012), a master student from College of Literature, Hebei University, Baoding, Hebei province, discriminates pangbian, fujin and zhouwei in terms of their semantic meanings and usages with the help of 《新法编排汉语词典》 (A New Chinese Dictionary) (compiled by Qizhi Wan et al 万启智等编 published by Xinhua Publishing House in 1985) and Shuxiang Lv's Eight Hundred Words (1980). Her conclusion is that the three localizers are the same in suggesting "being not far from the reference point", and they are different in whether the reference point is clearly indicated and how far away the object is from the reference point and in what direction. This paper is limited to Miss Li's discussion of the first two localizers. As to whether the reference point is clearly indicated, she thinks the two words are similar in that the reference point can be clearly indicated and it is also true the other way round, that is, the reference point is not clearly indicated. As to the distance from the reference point and the direction the object is in, Miss Li thinks that pangbian is the nearest and fujin is nearer. However, there is no strict rule to discriminate them and in many cases both can be chosen, which is the same as Fang Wang's first difference. Miss Li proposes that only fujin can be used with quantity phrases for distance. In terms of range and direction, Miss Li thinks that pangbian implies the left or the right side of the object, and has a direction. On the contrary, fujin suggests a certain distance away, on a whole piece of successive ground with indistinct direction.

From all the literature discussed above, it is still not easy to clearly distinguish between the two localizers fujin and pangbian.

\section{DISCRIMINATION BETWEEN FUJIN AND PANGBIAN}

Judged by Professor Fang's cognitive structure statement of the Chinese spatial location reference in 1999a\&b, fujin and pangbian are localizers since they both have the five structural elements of location reference, belonging to Group E which indicates general direction (1999b), in which there is no need to consider the direction reference point. As for the element narrator, the selection of the two localizers are not affected whether in case of the first person's point of view (自观), the narrator, that is, the third person's point of view (旁观) or the viewpoint of another person other than the person concerned or the narrator in a narrative (他观). As a result, the viewpoint of either the narrator or the person concerned or the another person does not need to be considered. According to Professor Fang, the location reference point is not indispensable. Nevertheless, I think the point, or rather the point at which the reference object exists, is of great importance to the discrimination between fujin and pangbian.

I think that fujin and pangbian can be discriminated from the following three aspects.

Use fujin rather than pangbian when barrier exists

Apart from the distance difference between the reference object and the object itself, whether there exists any barrier in between should be considered.

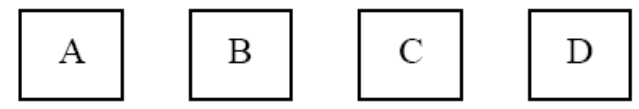

Figure 1. The effect of difference in sight line distance and barrier existence on the choice of fujin and pangbian.

In Figure 1, judged by Fang's judging criterion (1999a) that fujin is used when the sight line is farther, while pangbian, when the sight line is nearer, $\mathrm{C}$ and $\mathrm{D}$ are near $\mathrm{A}(\mathrm{C}$ 和 $\mathrm{D}$ 都在 A 的附近) and $\mathrm{B}$ is next to A (B 在 A 的旁 边). To A, C is nearer than D in sight line. However, it cannot be said that $\mathrm{C}$ is next to A because of the existence of B. In this case, I think it is better to divide the compound pangbian into pang and bian. Only when an object is on the side of the reference object and there is no barrier is in between can pangbian be used.

\section{Use fujin for spatial relationship while pangbian for horizontal relationship}

In 1994 Ningsheng Liu proposed that “甲在乙旁边 (A is near B) ” suggests that A is only a short distance away from $\mathrm{B}$ and they are of horizontal relationship. TCSOL teachers for beginners just go as far when explaining the two localizers. However at this point, the students cannot choose the right localizer when doing blank-filling exercises with fujin and pangbian. They usually have no problems with pangbian. Nevertheless, they will be confused sometimes with such sentences:

1. 从北极上空附近看地球呈逆时针, 从南极上空看呈顺时针。

(Seen from above the North Pole, the Earth turns anticlockwise; on the contrary, when seen from above the South Pole, it turns clockwise.) 


\section{2. 救援队在沉船海域附近展开搜救。}

(The rescue team is searching and rescuing over the area where the ship was sunk.)

It is obvious that in such cases distance relationship does not work. There is no fixed collocation ready for memorization. I think we can discriminate them spatially and horizontally. In general, pangbian suggests that the object concerned is at any point of the radius of the circle with "O" as the centre around the reference object, which can be any point, $\mathrm{a}, \mathrm{b}$ or $\mathrm{c}$ as shown in Figure 2. Nevertheless, fujin is any point on the circle, $\mathrm{c}$ or $\mathrm{d}$ when defined horizontally. But to be more exact, fujin should be any point over the sphere or the spherical surface, that is to say, thinking as with solid geometry in a space when defining fujin. In this way, why not pangbian but fujin is used after 上空 (the sky) is clear. As for the second example, since the rescue team is searching under the sea as well as on the sea, fujin rather than pangbian should be used to convey the spatial concept, including on the sea and below the sea as well.

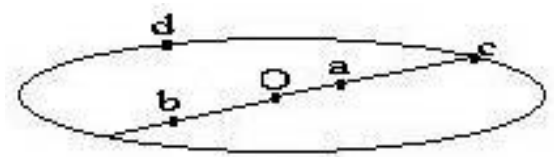

Figure 2. The sketch map of spatial fujin and horizontal pangbian.

If the object concerned is outside the domain of the reference object and belongs to a different position domain, the reference object can be seen as a point, and fujin and pangbian can be chosen using the above approach. However, in practice, the reference object is sometimes rather large. When the object is in the domain of the reference object, limited by the distance of the sight line, only pangbian is used. This is in accordance with Ms Wang's conclusion that fujin can only be used for off-domain reference while pangbian can be used for both off-domain and in-domain (Wang, 2005).

Use both with quantity phrases yet only fujin with indefinite quantity phrases

Sha Li finds that fujin can be used with definite quantity phrases for distance while pangbian cannot go with definite quantity phrases for distance. However, I think both localizers can be used with quantity phrases as in the following examples.

1. 山东淄博一化工厂发生爆炸 附近两公里内有震感

(A chemical plant exploded in Shandong, Zibo and the tremors were felt within two kilometres from the epicentre.)

(People's Network（人民网）, http://www.people.com.cn/, 22:09, 22 Aug 2015)

2. 工棚燃起熊熊大火旁边 50 米就是加油站

(The builder's sheds burst into flames, and 50 meters away was a gas station.)

(Yangtse Evening Post ( 《扬子晚报》) , http://www.yangtse.com/,15 Aug 2016)

Those who pay close attention to financial and economic news can often see such sentences as “大盘在 2600 点附近 震荡。(Market shocks in the vicinity of 2600 points.)” or “价格在 2 万元附近波动。(The price fluctuates around 20 thousand yuan.)". In such cases, fujin, used after quantity phrases, suggests “around” (上下、左右). Pangbian has no such meaning.

\section{CONCLUSIONS}

The Chinese localizers fujin and pangbian are known as an unavoidable tough confusing locative pair in TCSOL. However, the study of them still has much room. Based on the studies of Jingmin Fang, Ningsheng Liu, Fang Wang and Sha $\mathrm{Li}$, and through differentiating, this paper proposes three rules for the choice of the two localizers in practice: 1 . Use fujin when barrier exists; 2. Use fujin for spatial relationship and pangbian for horizontal relationship; and 3. Use both with quantity phrases yet only fujin with indefinite quantity phrases.

\section{ACKNOWLEDGMENTS}

The author wishes to thank Professor Zhong Chen of Beijing Languages and Culture University who taught me while I was doing my Master's degree in TCSOL. Under his encouragement, I conducted the research and wrote this paper.

\section{REFERENCES}

[1] Dictionary Compilation Faculty, Institute of Linguistics, Chinese Academy of Social Sciences. (2002). The contemporary Chinese dictionary (Chinese-English edition). Beijing: Foreign Language Teaching and Research Press.

[2] Fang, J. (1999a). Basic strategies in the cognitive process of Chinese spatial location reference. Studies of the Chinese Language 1, 12-20.

[3] Fang, J. (1999b). The cognitive structure of Chinese spatial location reference. Chinese Teaching in the World 4, 32-38.

[4] Hornby, A. S. Transl. Xiaoshu Shi et al. (2004). Oxford advanced learner's English-Chinese dictionary (6th ed). Beijing: The Commercial Press, second edition.

[5] Li, S. (2012). Discrimination of synonyms pangbian, fujin and zhouwei. Jiannanchun Literature 5, 88.

[6] Liu, N. (1994). How to express the spatial relationship of objects in Chinese. Studies of the Chinese Language 3, 169-179. 
[7] Lv, S. (Ed-in-chief). (1999). Modern Chinese eight hundred words (Enlarged revision). Beijing: The Commercial Press.

[8] Wang, F. (2005). Some semantic and cognitive features of some locatives. Chinese Linguistics 3, 78-84.

[9] Xia, Z., \& Chen, Z. (Eds-in-chief). (2009). An unabridged comprehensive dictionary (6th ed. with full-colour illustrations. Shanghai: Shanghai Lexicographical Publishing House.

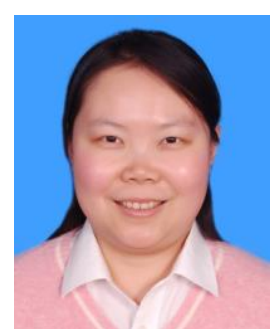

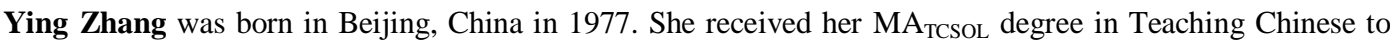
Students of Other Languages from Beijing Language and Culture University, Beijing, China in 2012; and received her $\mathrm{BS}_{\text {Computer \& Its Applications }}$ from Peking University, Beijing, China in 2006.

She is currently a LECTURER in Public Education Department of Tianjin College, University of Science \& Technology Beijing, located in Baodi District, Tianjin, China, teaching College Chinese, Modern Chinese, Traditional Chinese Culture, and Theories and Practice on TCSOL. She worked as part-time LECTURER teaching Chinese to students of other languages at the International Office, University of Science \& Technology Beijing, Beijing, China from 2008 to 2013. Three of her previous published papers are "A study of Chinese degree complement acquisition based on HSK Dynamic Composition Corpus" in Xiliang Cui and Baolin Zhang's Selected Papers of The Second International Symposium on the Construction and Application of the Corpus of Chinese published by Beijing Language and Culture University Press, Beijing, China in 2013, "Group-activity- and new-lessonbased student questioning in college Chinese teaching" in Journal of Language Teaching and Research (JLTR), Vol. 7, No. 5:979984 in 2016 and "40 Years' Argument on College Chinese: On the Name of the Course" in Journal of University of Science and Technology Beijing (Social Sciences Edition), Vol. 33, No. 5:102-106 in 2017. Her current and previous research interests include teaching Chinese to native speakers and students of other languages. 